Fifth International Conference on Sustainable Construction Materials and Technologies. http://www.claisse.info/Proceedings.htm

\title{
USING DIFFERENT TYPES OF AGGREGATES INCLUDING WASTE CONCRETE IN THE PRODUCTION OF GEOPOLYMER MORTARS
}

\author{
Orhan Canpolat ${ }^{1}$, Furkan Şahin ${ }^{2}$, Mucteba Uysal ${ }^{2}$, \\ Mukhallad M. Al-Mashhadani ${ }^{3}$, and Yurdakul Aygörmez ${ }^{1}$
}

${ }^{1}$ Yildiz Technical University, Faculty of Civil Engineering, Civil Engineering Department, Davutpasa Campus, Istanbul, Turkey, E-mail: 〈canpolat@yildiz.edu.tr>, <aygormez@yildiz.edu.tr>,

${ }^{2}$ Istanbul University Cerrahpasa, Engineering Faculty, Civil Engineering Department, Avcilar campus, Istanbul, Turkey, E-mail: <mucteba.uysal@istanbul.edu.tr>, $<$ furkansahintr@gmail.com>

${ }^{3}$ Istanbul Gelişim University, Civil Engineering Department, Avcilar Campus, Istanbul, Turkey, E-mail: 〈mashhadani@gelisim.edu.tr>

\begin{abstract}
In developed and developing countries, the need for industrial and residential buildings is constantly increasing. The old buildings are either demolished or replaced by new buildings in order to maintain environmental awareness and due to limited usage areas. In this construction process, traditional Portland cement is used and also a serious solid waste problem arises due to the demolished buildings. Because of using Portland cement, a significant amount of greenhouse gas production is generated, as well as high levels of environmental pollution due to the accumulation of concrete solid wastes. New laws have been enacted in many countries to reduce greenhouse gas emissions due to Portland cement and for solid waste management, and even the establishment of recycling facilities for waste concrete has been encouraged. The reduction of greenhouse gas emissions and recycling of construction wastes have gained great importance both because of the protection of the natural environment and its contribution to the economy.In this study, more environmentally friendly geopolymer additives were used instead of traditional Portland cement for the recycling of construction waste, as well as geopolymer mortars were produced with different types of aggregates. The $0.4 \%$ basalt fiber additive series of the obtained samples were similarly produced. The geopolymer samples produced by using different aggregate types including the waste concrete aggregate were compared in terms of 28 days compressive strengths, ultrasound velocities, unit weight, voids ratio and water absorption results.
\end{abstract}

Keywords: Sustainable; Geopolymer; Metakaolin; Slag; Basalt Fiber; Waste Concrete 


\section{INTRODUCTION}

Cement production accounts for 5-7\% of the total emissions in the world and approximately $17 \%$ of the total emissions from the construction industry, therefore it is one of the most important reasons for global warming. In order to find solutions to the results of this situation, a large number of studies have been carried out in the construction industry regarding the whole or partial replacement of Portland cement with substitute cementitious materials. The most important study on this subject has been the production of geopolymer [Duxson et al., 2007].

Geopolymer is produced by the reaction of alkaline activators with fly ash, metakaolin, blast furnace slag, and rice husk which have a high proportion of silicon $(\mathrm{Si})$ and aluminium $(\mathrm{Al})$ to produce cement-like binders [Davidovits, 1994].

Concrete wastes are obtained from demolished buildings, sidewalks, bridges, etc. These wastes can be evaluated as aggregates in newly produced concretes by decreasing the usage rate of natural aggregates. The recycled concrete aggregate, which provides a significant advantage with its use in this way, has a significant effect on the properties of the newly produced concrete due to the porous structure on the surface resulting from the cement mortar in which it is produced [Amer et al., 2016]. In addition, it has been observed that geopolymer concrete produced by using recycled aggregates improves the transport and strength properties of the geopolymer concrete [Nuaklong et al., 2018].

It has been observed that the concrete produced by using basalt aggregates has higher strength than the concrete produced by limestone, and this is due to its intrinsic strength of the rock [Rozalija and Darwin, 1997]. It has been shown to be advantageous to use basalt aggregates to increase impact strength, especially at higher loading rates, as cracks can form and spread rapidly. Using basalt aggregate to improve both mechanical properties and impact strength appears to have a significant effect [Tai et al., 2016]. In addition, basalt fiber reinforced samples had higher strength properties than non-fiber samples. This is due to the fact that the addition of basalt fiber to the geopolymeric matrix provides a significant improvement [Celik et al., 2018].

There are limited number of studies on the using waste concrete and basalt as aggregate in the production of geopolymer mortar. In this study, this situation was taken into consideration and aggregate sand as well as basalt and waste concrete were added to the geopolymer mortar sample. The $0.4 \%$ basalt fiber additive series of the obtained samples were similarly produced. The results of 28 days compressive strengths of all samples were compared. In addition, ultrasound velocities, unit weight, porosity and water absorption results were examined.

\section{MATERIALS AND METHODS}

\section{Experimental Study}


The amounts of mixture used in this study are shown in Table 1. During the preparation of the mixture, the studies were taken into consideration in the literature [Lahoti et al. 2017], [Burciagadíaz et al., 2016]. One day before the mixture was made, sodium hydroxide solution was prepared and left to cool down. Sodium silicate and sodium hydroxide solution were mixed on the day of the mixture and then mixed with $450 \mathrm{~g}$ metakaolin. $60 \mathrm{~g}$ slag was added to increase the calcium ratio of the mixture. Then, as aggregates, waste concrete, basalt and standard sand were added to the geopolymer paste. The prepared mixture was placed in the moulds and kept at room temperature for 24 hours after exposure to vibration. Samples for curing were then kept in a plastic bag for 72 hours at $60^{\circ} \mathrm{C}$ [Uysal et al, 2018]. All series were produced with $0.4 \%$ basalt fiber additives. In this study standart sand, recycled concrete, basalt, basalt fiber, denotes SS, RC, $\mathrm{B}, \mathrm{BC}$, respectively.

Table 1. Geopolymer mortar mixing proportions (g)

\begin{tabular}{|c|c|c|c|c|}
\hline Metakaolin & $\begin{array}{c}\text { Sand (waste } \\
\text { concrete, basalt } \\
\text { and standart) }\end{array}$ & $\mathrm{NaOH}(12 \mathrm{M})$ & $\mathrm{Na}_{2} \mathrm{SiO}_{3}$ & Slag \\
\hline 450 & 1125 & 150 & 300 & 60 \\
\hline
\end{tabular}

\section{MATERIALS}

\section{Metakaolin and Slag}

In this study, slag was provided from Bolu Cement Company (Bolu /Turkey) and metakaolin was provided from Kaolin EAD (Turkey, Istanbul). The specific gravities of slag, metakaolin are 2.91 $\mathrm{g} / \mathrm{cm}^{3}$ and $2.52 \mathrm{~g} / \mathrm{cm}^{3}$, respectively. The chemical composition of the binders are shown in Table 2.

Table 2. Chemical composition of metakaolin and slag (\%)

\begin{tabular}{|c|l|l|l|l|l|l|l|l|l|}
\hline $\begin{array}{c}\text { Chemical analysis, } \\
\%\end{array}$ & $\mathrm{SiO}_{2}$ & $\mathrm{Al}_{2} \mathrm{O}_{3}$ & $\mathrm{Fe}_{2} \mathrm{O}_{3}$ & $\mathrm{TiO}_{2}$ & $\mathrm{CaO}$ & $\mathrm{MgO}$ & $\mathrm{K}_{2} \mathrm{O}$ & $\mathrm{Na}_{2} \mathrm{O}$ & L.O.I. \\
\hline Metakaolin & 56.10 & 40.23 & 0.85 & 0.55 & 0.19 & 0.16 & 0.51 & 0.24 & 1.10 \\
\hline Slag & 40.55 & 12.83 & 1.10 & 0.75 & 35.58 & 5.87 & 0.68 & 0.79 & 0.03 \\
\hline
\end{tabular}

\section{Activator}

Sodium hydroxide solutions and sodium silicate solutions were used as alkali activators in this study. They were provided from Merck. Sodium silicate solution has a molar ratio of 3.29. Sodium hydroxide solution was prepared as $12 \mathrm{M}$.

\section{Aggregate}

For this study, standard sand which is according to BS EN 196-1 was added. Basalt and waste concrete were also used as aggregate.

\section{Fiber}

For this study, basalt fiber shown in Table 3 was used. 
Table 3. Properties of basalt fiber

\begin{tabular}{|c|c|c|c|c|}
\hline & Length $(\mathrm{mm})$ & Diameter $(\mu \mathrm{m})$ & Specific Gravity & $\begin{array}{c}\text { Nominal Tensile } \\
\text { Strength (Mpa) }\end{array}$ \\
\hline Basalt Fiber & 12 & 20 & 2.73 & 4100 \\
\hline
\end{tabular}

\section{EXPERIMENTAL RESULTS}

For this study, the compressive and flexural strength results at 28 days are compared for three kinds of aggregate. Also effect of fibers are showed in Figure 1-2. The results showed that geopolimer samples with basalt sand showed the best performance. According to the geopolymer samples using standard sand, with waste concrete aggregate acceptable results and significant advantages have been obtained with respect to environmental protection and sustainability [Nuaklong et al., 2018]. Basalt fibers increased the compressive strength as well as the flexural strength, which is also consistent with previous studies [Celik et al., 2018]. According to the obtained results, the compressive strengths increased between $23.56 \%$ and $28.04 \%$ by fiber, while the increase in flexural strength was between $10.13 \%$ and $21.08 \%$.

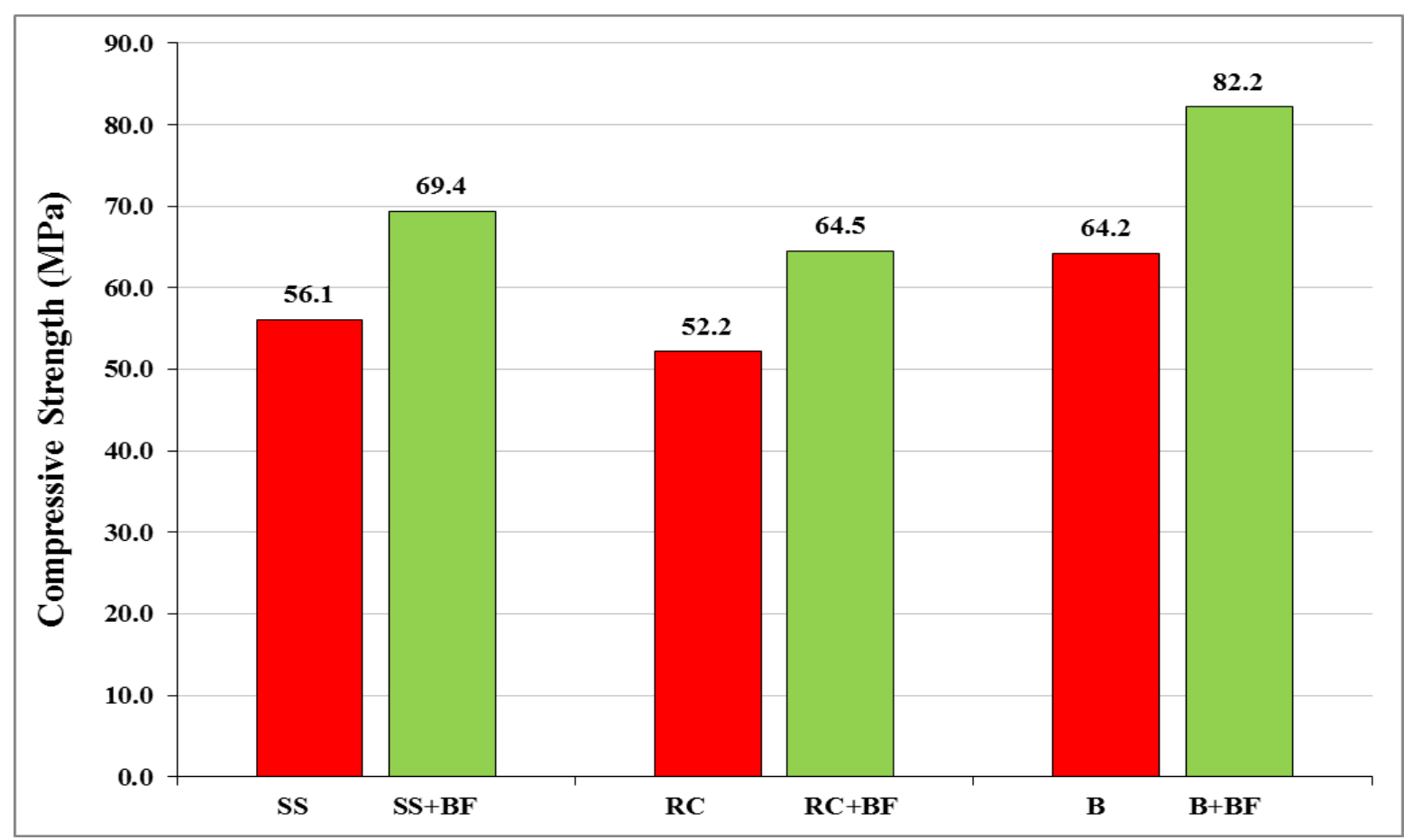

Figure 1. 28 days compressive strength test results 


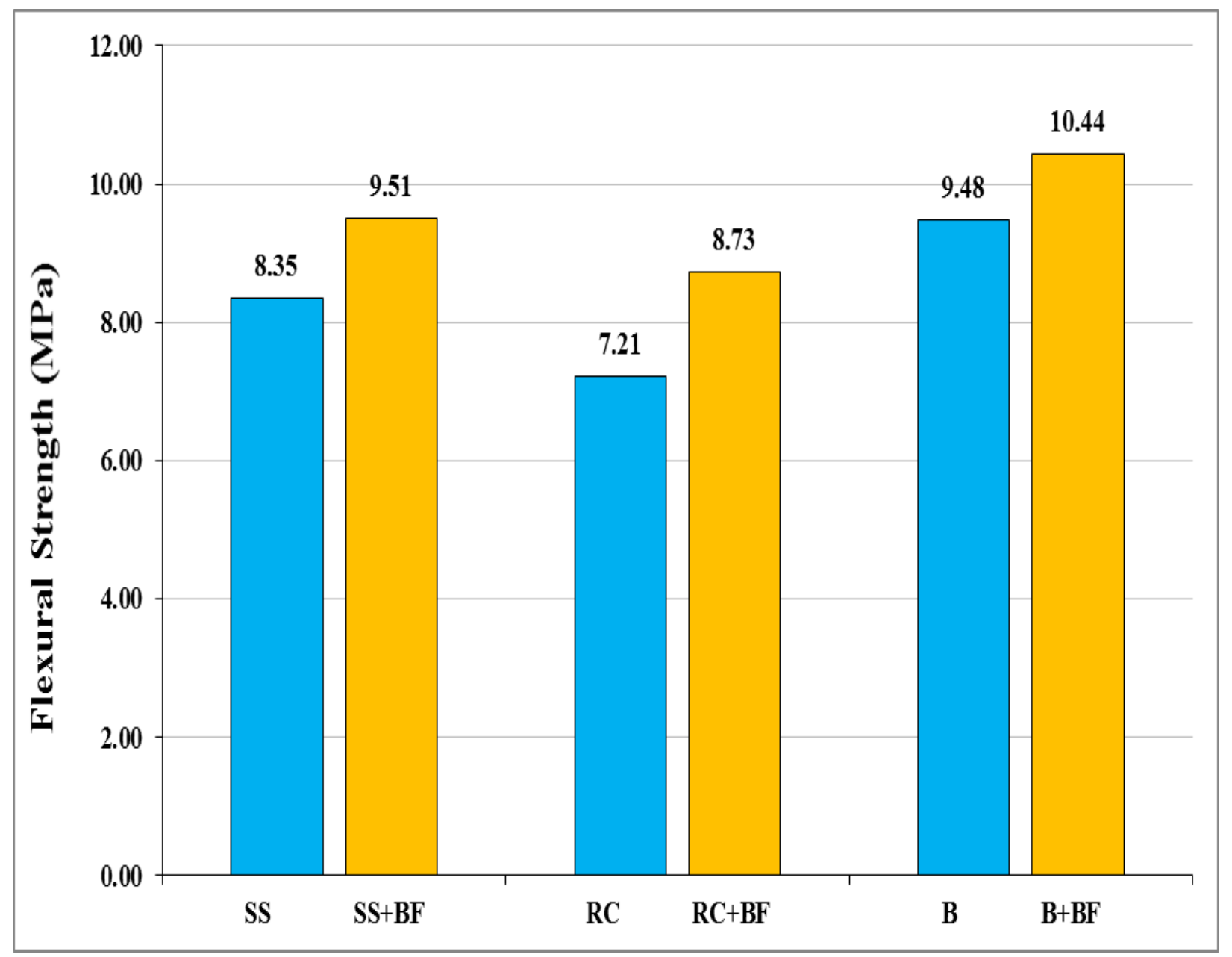

Figure 2. 28 days flexural strength test results

In the case of using waste concrete, the best results were obtained for ultrasound velocity test. The main reason for this situation is the fact that the waste concrete contains Portland cement. A slight improvement in ultrasound velocity test results was observed by the addition of basalt fibers. With the addition of basalt fiber, the rate of increase in ultrasound velocity test was between $0.63 \%$ and $1.39 \%$. This provides information that the fibers do not affect the homogeneity of the geopolymer matrix [Al-mashhadani et al., 2018]. Ultrasound velocity test results was showed in Figure 3. 


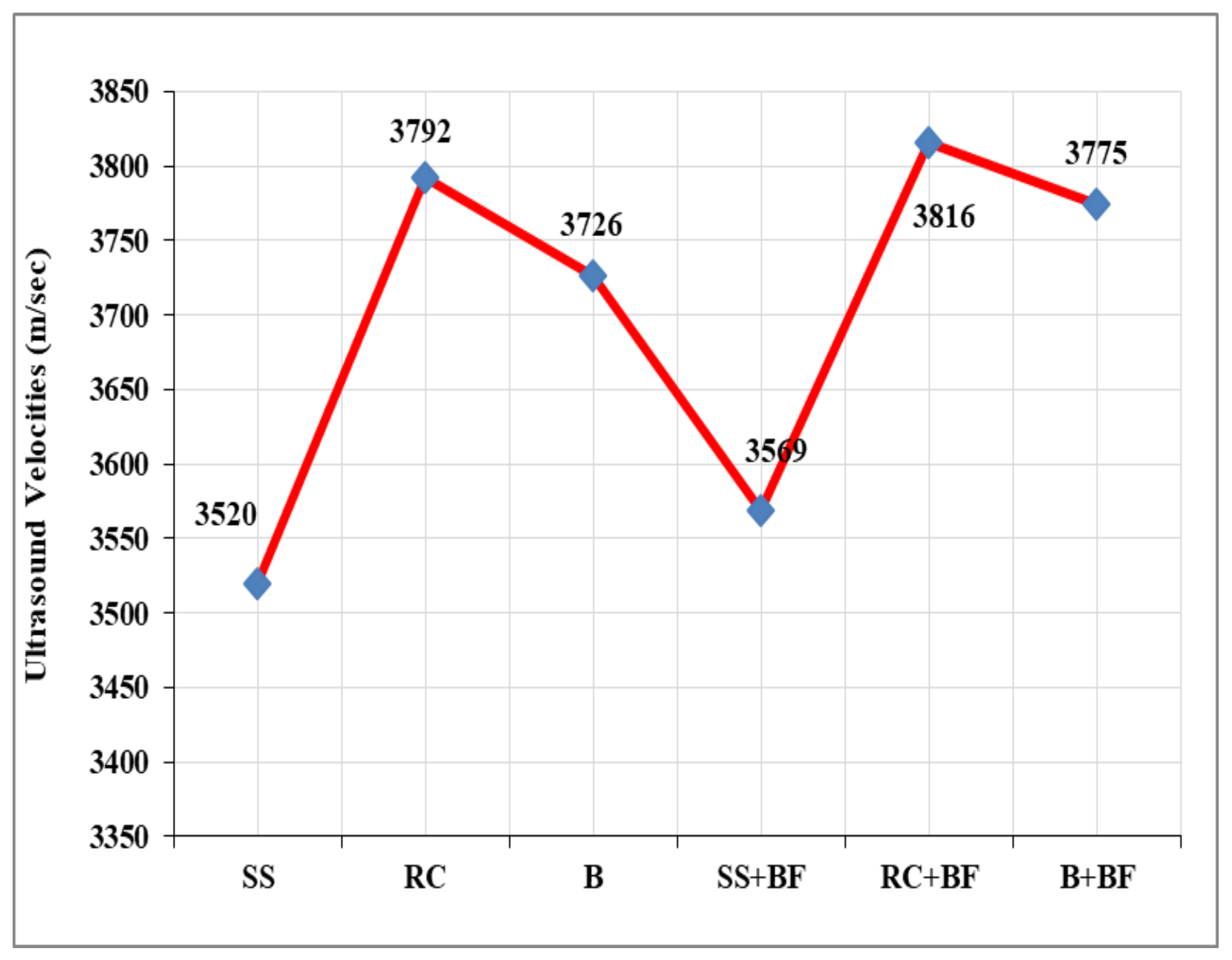

Figure 3. 28 days ultrasound velocity test results

When water absorption and voids ratio properties were examined, it is concluded that there is a slight improvement with fiber additive. The water absorption of the geopolymer sample is reduced due to the water absorption capacity of the basalt fiber. Thus, the amount of water absorbed by the geopolymer matrix decreased with the basalt fiber. Similarly, voids ratio results were obtained. The results showed an increase in unit weight with fiber additive. The results were consistent with other studies [Uysal et al, 2018], [Celik et al., 2018]. When geopolymer samples were examined in terms of three different aggregates, the results were close to each other (Table 4). 
Table 4. Physical properties of geopolymer mortar samples

\begin{tabular}{|c|c|c|c|}
\hline & Voids ratio (\%) & Unit weight $\left(\mathrm{g} / \mathrm{cm}^{3}\right)$ & Water absorption (\%) \\
\hline SS & 25 & 2.39 & 14 \\
\hline RC & 32 & 2.35 & 20 \\
\hline B & 25 & 2.44 & 14 \\
\hline RS+BF & 24 & 2.40 & 13 \\
\hline RC+BF & 29 & 2.41 & 17 \\
\hline B+BF & 24 & 2.47 & 13 \\
\hline
\end{tabular}

\section{CONCLUSIONS AND RECOMMENDATIONS}

The results of the study are listed below:

- Geopolymer samples with basalt sand showed the best performance for compressive and flexural tests.

- Geopolymer mortar samples with waste concrete aggregates showed acceptable results comparing to the other geopolymer samples.

- Geopolymer mortar samples with waste concrete aggregates shows significant advantages with respect to environmental protection and sustainability. More work using waste concrete should be done in this area.

- The highest results were observed in the geopolymer mortar samples with waste concrete aggregates in the ultrasound velocity test since it contains Portland cement. It was observed that the fiber additive did not make a significant change in the ultrasound velocity.

- In terms of physical properties, it was observed that fiber additive had a positive effect on the results. While the voids ratio and water absorption decreased with the fiber admixture, the unit weight increased.

\section{ACKNOWLEDGEMENT}

This work was supported by research fund of the Yildiz Technical University, the authors would like to express their sincere gratitude to scientific research coordination unit for their financial support to the project (Project number: 2016-05-01-DOP04. 


\section{REFERENCES}

Duxson P., Fernández-Jiménez A., Provis J.L., Lukey G.C., Palomo A. and van Deventer J.S.J. (2007). "Geopolymer technology: the current state of the art." J. Mater. Sci. 42 (9), 2917-2933.

Davidovits, J. (1994). "Properties of geopolymer cements, in: First International Conference on Alkaline Cements and Concretes." Kiev, Ukraine, p. 131- 149.

Amer, A.A.M., Ezziane, K., Bougara, A. and Adjoudj, M.H. (2016). "Rheological and mechanical behavior of concrete made with pre-saturated and dried recycled concrete aggregates." Constr. Build. Mater. 123, 300-308.

Nuaklong, P., Sata, V. and Chindaprasirt, P. (2018). "Properties of metakaolin-high calcium fly ash geopolymer concrete containing recycled aggregate from crushed concrete specimens." Construction and Building Materials 161, 365-373.

Rozalija, K. and Darwin, D. (1997). "Effects of Aggregate Type, Size, and Content on Concrete Strength and Fracture Energy.” Lawrence, Kansas.

Tai, Y.S., El-Tawil, S. and Chung, T.H. (2016). "Performance of deformed steel fibers embedded in ultra-high performance concrete subjected to various pullout rates." Cem. Concr. Res. 89, 1-13.

Celik, A., Yilmaz, K., Canpolat, O., Al-mashhadani, M.M., Aygörmez, Y. and Uysal, M. (2018). "High-temperature behavior and mechanical characteristics of boron waste additive metakaolin based geopolymer composites reinforced with synthetic fibers." Construction and Building Materials 187, 1190-1203.

Al-mashhadani, M.M., Canpolat, O., Aygörmez, Y., Uysal, M. and Erdem, S. (2018). "Mechanical and microstructural characterization of fiber reinforced fly ash based geopolymer composites.” Constr. Build. Mater. 167, 505-513.

Lahoti, M., Narang, P., Tan, K.H.and Yang, E. (2017). "Mix design factors and strength prediction of metakaolin-based geopolymer.” Ceram. Int. 43 (14), 11433-11441.

Burciaga-díaz, O., Gómez-zamorano, L.Y. and Escalante-garcía, J.I. (2016). "Influence of thelong term curing temperature on the hydration of alkaline binders of blastfurnace slag-metakaolin." Constr. Build. Mater. 113, 917-926.

Uysal, M., Al-mashhadani, M.M., Aygörmez, Y. and Canpolat, O. (2018). "Effect of using colemanite waste and silica fume as partial replacement on the performance of metakaolin-based geopolymer mortars." Constr. Build. Mater. 176, 271-282. 